\title{
Plasma glucose and nonesterified fatty acids response to epinephrine challenges in dairy cows during a 670-d lactation
}

\author{
L. C. Marett, ${ }^{* 1}$ M. J. Auldist, ${ }^{*}$ W. J. Wales, ${ }^{*}$ K. L. Macmillan,† F. R. Dunshea, $†$ and B. J. Leury† \\ *Department of Economic Development, Jobs, Transport and Resources, Agriculture Victoria, Ellinbank, Victoria 3821, Australia \\ †Faculty of Veterinary and Agricultural Science, The University of Melbourne, Parkville, Victoria 3010, Australia
}

\begin{abstract}
This experiment investigated the metabolic response to a 2-dose epinephrine challenge of dairy cows undergoing an extended lactation. Twelve multiparous Holstein-Friesian cows that calved in late winter in a seasonally calving pasture-based dairying system were managed for a $670-d$ lactation by delaying rebreeding. In each of four 40-d experimental periods commencing at $73,217,422$, and $520( \pm 9.1)$ d in milk (DIM), cows were offered a diet of perennial ryegrass (73 and 422 DIM) or pasture hay and silage (217 and 520 DIM), supplemented with $1(\mathrm{CON} ; \mathrm{n}=6)$ or $6 \mathrm{~kg}$ of grain $(\mathrm{GRN} ; \mathrm{n}=6)$ as a ration. Daily energy intake was approximately 160 and 215 MJ of metabolizable energy/ cow for the CON and GRN treatments, respectively. At all other times, cows were managed as a single herd and grazed pasture supplemented with grain to an estimated daily total intake of $180 \mathrm{MJ}$ of metabolizable energy/ cow. Cows were fitted with a jugular catheter during the final week of each experimental period. Two doses of epinephrine (0.1 and $1.6 \mu \mathrm{g} / \mathrm{kg}$ of body weight) were infused via the catheter $2 \mathrm{~h}$ apart to each cow at approximately 100, 250, 460, and 560 DIM. Blood plasma concentrations of glucose and nonesterified fatty acids (NEFA) were measured before and after infusions. Cows in the GRN treatment had greater milk yield, milk fat and protein yields, and body weight than cows in the CON treatment. The maximum plasma glucose concentration was observed at 100 DIM for both the low and high doses of epinephrine. Thus, sensitivity and responsiveness to exogenous epinephrine were greater during early lactation, coinciding with increased priority of milk synthesis. Both the sensitivity and responsiveness to epinephrine decreased with decreasing milk yield, as measured by the acute appearance of NEFA in the plasma. Increased plasma glucose and NEFA clearance rates before 300 DIM indicated greater uptake of these
\end{abstract}

Received July 31, 2017.

Accepted November 27, 2017

${ }^{1}$ Corresponding author: leah.marett@ecodev.vic.gov.au substrates by the mammary gland for milk synthesis in early and mid lactation. These results support previous findings that major changes occur in terms of adipose tissue metabolism during extended lactations. Overall, sensitivity to epinephrine was not affected by diet, but responsiveness was greater in cows fed the GRN diet. The endocrine regulation of nutrient partitioning throughout traditional and extended lactations is complex, with many interactions between stage of lactation, diet, and milk yield potential.

Key words: extended lactation, fat mobilization, nutrient partitioning

\section{INTRODUCTION}

Large variation exists between cows in their capacity for undergoing lactations of up to $670 \mathrm{~d}$ in duration when predominantly fed grazed pasture (Auldist et al., 2007; Kolver et al., 2007; Grainger et al., 2009). Some of this variation has been explained by differences in the partitioning of nutrients between body stores and milk production. Cows that were not able to complete a 670-d lactation gained more BW and BCS than those that were able to continue milking (Auldist et al., 2007; Delany et al., 2010; Marett et al., 2011). Dietary restriction under grazing conditions did not decrease the proportion of cows with greater lactation persistency (Delany et al., 2010; Marett et al., 2011). Less persistent cows have greater plasma leptin concentrations beyond 300 DIM, indicating that an increase in fat mass occurs as milk production decreases with advancing lactation (Kay et al., 2009; Delany et al., 2010; Marett et al., 2011). The greatest lipolytic response to epinephrine occurs around the time of peak milk production, and is positively related to milk energy secretion (McNamara, 1988). As lactation progresses beyond the traditional $300 \mathrm{~d}$, the rate of lipolysis may be decreased or rate of lipogenesis increased, or both; thus, the adipose tissue responsiveness or sensitivity to catecholamines is potentially reduced as milk yield declines.

A substantial increase in demand for energy occurs after parturition in the dairy cow (Drackley et al., 2001). 
Metabolic and endocrine adaptations occur in response to deficits of certain substrates for maintenance and milk production. These promote mobilization from tissues stores, such as adipose tissue, during early lactation in response to insufficient feed intake (Collier et al., 1984). Nonesterified fatty acids (NEFA) released as a result of adipose tissue mobilization are one of the main energy sources for the dairy cow during times of negative energy balance in early lactation and fasting (Ferrannini et al., 1997). Thus, the requirement for fatty acids decreases as lactation progresses and milk yield declines. The effects of nutrition on adipose tissue metabolism are affected by both stage of lactation and cow genetics, with possible interactions between them (Roche et al., 2009).

Epinephrine is a potent regulator of adipose tissue metabolism (Rubinstein et al., 1964; Wagle et al., 1976). It acts via specific receptors on target tissues to promote the supply of energy intermediates, such as fatty acids and glucose, to tissues such as the mammary gland (McCutcheon and Bauman, 1986; McNamara and Hillers, 1986; McNamara, 1988). The bovine response to administration of epinephrine and norepinephrine includes increased lipolysis (McNamara and Hillers, 1986; Sechen et al., 1990), release of glucose from glycogen stores in the liver, and increased hepatic gluconeogenesis (Rose et al., 2009). McNamara and Hillers (1986) reported that energy intake did not affect the rate of lipolysis in response to epinephrine for the first $140 \mathrm{~d}$ postpartum. Kolver at al. (2001) also reported no difference in the glycerol or NEFA response to an epinephrine challenge in cows fed grazed pasture or a TMR in early lactation. However, they did show that the glucose response to epinephrine was greater in cows offered a TMR compared with those that grazed pasture. No information is currently available on the responsiveness and sensitivity of bovine adipose tissue to catecholamines throughout an extended lactation.

The greatest changes throughout extended lactations appear to occur not in glucose metabolism but in fatty acid metabolism (Marett et al., 2015). Marett et al. (2017) observed a large degree of variation in the plasma NEFA response to an intravenous glucose tolerance test and an insulin tolerance test at 4 stages of a $670-d$ lactation. The intravenous glucose tolerance test and insulin tolerance test allow investigators to assess the anti-lipolytic effect of endogenous and exogenous insulin, respectively; however, these tests are unable to assess the lipolytic capacity of adipose tissue throughout lactation. The increased rate of plasma NEFA reentry into the blood following an insulin infusion in dairy cows highlighted possible variation in counterregulatory hormone [such as growth hormone $(\mathbf{G H})$ or epinephrine] secretion in response to insulin-induced hypoglycemia (Marett et al., 2017). Growth hormone regulates adipose stores by enhancing the response to lipolytic stimuli (Liesman et al., 1995). Marett et al. (2014) showed a decrease in plasma concentration of GH throughout an extended lactation, but lower basal GH concentrations in cows fed a greater amount of grain, indicating variation in the regulation of nutrient partitioning, in particular in adipose tissue, beyond 300 DIM. However, the effects of diet on adipose tissue metabolism at different stages of lactation are inconsistent (Roche et al., 2009).

An improved understanding of the regulation of adipose tissue metabolism is important for developing nutritional strategies for cows managed for extended lactations. The aim of our experiment was to investigate variation in sensitivity and responsiveness of dairy cows to an exogenous catecholamine infusion at different stages of a 670-d lactation and determine the effect of supplementary grain feeding on these responses. We hypothesized that (1) the sensitivity to a low dose of exogenous epinephrine, as measured by the plasma glucose and NEFA responses, would decrease with increasing DIM; (2) the responsiveness to a high dose of epinephrine, as measured by the plasma glucose and NEFA responses, would decrease with increasing DIM; (3) the sensitivity to epinephrine would not be affected by dietary intake of cereal grain; and (4) the responsiveness to epinephrine would not be affected by dietary intake of cereal grain.

\section{MATERIALS AND METHODS}

\section{Location}

This experiment was conducted at the Department of Economic Development, Jobs, Transport and Resources' Ellinbank Centre in Victoria, Australia (latitude $38^{\circ} 14^{\prime} \mathrm{S}$, longitude $145^{\circ} 56^{\prime} \mathrm{E}$ ). The experiment was conducted in accordance with the Australian Code of Practice for the Care and Use of Animals for Scientific Purposes (NHMRC, 2004). Approval to proceed was obtained from the Department of Economic Development, Jobs, Transport and Resources Agricultural Research and Extension Animal Ethics Committee.

\section{Cows and Management}

The experimental design has been described in detail by Marett et al. (2015). Briefly, the experiment used 12 multiparous Holstein-Friesian cows of mixed age that calved in late July (winter). These cows were a subset of those used in the experiments of Auldist et al. (2011). The cows were managed for an extended lactation by delaying breeding until $\sim 450$ DIM for a target lactation 
length of $670 \mathrm{~d}$. All cows were managed as a single herd for the majority of their lactations and grazed perennial ryegrass (Lolium perenne) pasture supplemented with cereal grain fed twice daily in the dairy at milking times. When pasture was limited during the summer and autumn months, pasture hay (approximately $6 \mathrm{~kg}$ of DM/cow per day) and pasture silage (approximately $10 \mathrm{~kg}$ of DM/cow per day) were also offered to achieve an estimated daily intake of $180 \mathrm{MJ}$ of $\mathrm{ME} /$ cow.

We used 4 experimental periods of up to $40 \mathrm{~d}$ during these lactations, beginning at each of $73,217,422$, and $520( \pm 9.1)$ DIM. Two treatments were allocated randomly to each of 6 cows. Treatment groups were balanced for parity, calving date, BW, and yields of milk, fat, and protein in the preceding lactation (Baird, 1994). During the experimental periods, control $(\mathbf{C O N})$ cows were fed $1 \mathrm{~kg}$ of DM grain/d and treatment (GRN) cows were fed $6 \mathrm{~kg}$ of DM grain/d. Cows were milked twice daily at $\sim 0700$ and $1500 \mathrm{~h}$, with $50 \%$ of the total daily grain intake fed individually at each milking. Forage and freshly cut pasture were fed twice daily in individual feed bins while cows were restrained in stalls. The targeted total ME intake was approximately 160 MJ of ME/cow per day for the CON treatment and 215 MJ of ME/cow per day for the GRN treatment. Cows were released from stalls to a loafing pad after they had eaten, and cows had access to fresh water ad libitum. Cows were relocated to metabolism stalls $5 \mathrm{~d}$ before the end of each experimental period. Cows were fitted with harnesses to remove feces and urine and were milked in place. Each cow underwent a $>18$-h adjustment period, followed by a 24 -h sampling period, and then a series of 3 metabolic challenges (glucose, insulin, and epinephrine) over 3 consecutive days. Each cow underwent 1 metabolic challenge per day. The order of challenges changed with experimental period. Data from the intravenous glucose tolerance test are presented in Marett et al. (2015), and data from the insulin tolerance test are presented in Marett et al. (2017). The epinephrine challenges were conducted during this time when cows were at $\sim 100,250,460$, and 560 DIM.

The dry-off threshold and breeding program were implemented as described previously by Auldist et al. (2007). Some cows were removed from the experiment because their milk yield fell below the dry-off threshold (30 kg/cow per week for 2 consecutive weeks) or because of unrelated health issues. During the course of the 4 experimental periods, $4 \mathrm{CON}$ and 2 GRN treatment cows were replaced with cows of comparable age, DIM, and milk yield.

Milk yield, nutrient intake, and BW were measured as described in Marett et al. (2015). Milk yield and feed intake were measured twice daily, whereas BW was measured at the start and end of each experimental period.

\section{Epinephrine Challenge}

Each cow was fitted with an indwelling jugular catheter for ease of sampling and then rested for at least $24 \mathrm{~h}$ before the first sampling. Each cow was sampled 7 times via the jugular catheter over a 24 -h period at 4-h intervals commencing at $0800 \mathrm{~h}$. Epinephrine challenges were performed on each cow within the following $3 \mathrm{~d}$. Cows had feed removed for $12 \mathrm{~h}$ before the challenge. Epinephrine challenges were of a 2-dose design to assess both sensitivity and responsiveness and were conducted with sampling beginning at $0800 \mathrm{~h}$ at the 4 experimental periods. Samples were taken at $-20,-10$, and $1 \mathrm{~min}$ before infusion of the low dose $(0.1 \mu \mathrm{g} / \mathrm{kg}$ of BW epinephrine, made up to $5 \mathrm{~mL}$ in saline, and 1 $\mathrm{mg} / \mathrm{mL}$ of Adrenaline Injection BP; AstraZeneca, Macquarie Park, Australia) through the catheter followed by $60 \mathrm{~mL}$ of heparinized saline $(50 \mathrm{U} / \mathrm{mL})$. Follow-up samples were taken at $2,4,6,8,10,12,15,18,20,23$, $26,30,35,40,50,60,90,105$, and $120 \mathrm{~min}$ after the low dose infusion. Immediately following the 120-min sample, the high dose $(1.6 \mu \mathrm{g} / \mathrm{kg}$ of $\mathrm{BW}$ epinephrine, made up to $5 \mathrm{~mL}$ in saline) was infused via the catheter followed by $60 \mathrm{~mL}$ of heparinized saline $(50 \mathrm{U} / \mathrm{mL})$. Samples were then taken at the same time intervals as for the low dose as well as 150 and 180 min after the high dose infusion. Catheters were flushed with $10 \mathrm{~mL}$ of heparinized saline after each blood sample to maintain patency. Each blood sample was collected into a $10-\mathrm{mL}$ heparinized vacutainer (BD Vacutainer Systems, Plymouth, UK), then immediately chilled on ice before being centrifuged at 1,800 $\times g$ for $10 \mathrm{~min}$ at $4^{\circ} \mathrm{C}$ within $1 \mathrm{~h}$ of collection. Plasma was decanted and stored at $-20^{\circ} \mathrm{C}$ until analyzed for glucose and NEFA concentrations. The 2 doses for epinephrine challenge were chosen to elucidate approximately 30 and $100 \%$ of the maximal NEFA response to epinephrine (Sechen et al., 1990), and thus provided an estimate of sensitivity and responsiveness, respectively.

Plasma samples from the 24-h sampling period (collected, processed, and stored as indicated above) were analyzed for concentrations of NEFA and leptin (plasma insulin and glucose from this period are reported in Marett et al., 2017). Samples from the epinephrine challenges were analyzed for concentrations of glucose and NEFA. Plasma leptin concentrations were measured by a double-antibody RIA (Blache et al., 2000). Plasma glucose concentrations were measured using a commercially available kit (Thermo Infinity Glucose Oxidase Liquid, Thermo Fisher, Noble Park, Victoria, 
Australia). Plasma NEFA concentrations were measured using the commercially available Wako NEFA-C kit (Wako Chemicals USA, Richmond, VA) adapted for 96-well microplates (Johnson and Peters, 1993). Every sample was assayed in duplicate. All samples measured for leptin were processed in a single assay with an intra-assay coefficient of variation of $<8.5 \%$. Intra- and interassay coefficients of variation for glucose were $<3$ and $<5.5 \%$, respectively, and for NEFA were $<4$ and $<6 \%$, respectively.

\section{Calculations and Statistical Analyses}

The trapezoidal method was used to calculate the area under the response curve above baseline (AUC) for each set of plasma glucose and NEFA samples. Appearance rates $(\mathbf{A R})$ and clearance rates $(\mathbf{C R})$ were expressed as the apparent fractional rate of change for a given time period and were determined from the slope of the natural logarithm of the plasma concentration (glucose or NEFA) plotted against time. The change in plasma glucose and NEFA were calculated as the difference between the maximum and basal concentration as a percentage of the basal concentration.

Data were analyzed for differences in response measures at each of the 4 selected stages of each lactation (100, 250, 460, and 560 DIM) and between dietary treatments using a mixed model with REML (GenStat11.0; VSN International Ltd., Hemel, Hempstead, UK). The model included fixed effects for DIM and diet, with the cow as the random effect. For the 24-h sampling, the average of the plasma NEFA or leptin concentration of the 7 samples collected was used. For each plasma parameter, basal values were calculated by taking the average of the 3 samples before epinephrine infusion of each epinephrine challenge. Recovery values were calculated as the average of the final 3 samples. Skewed data for AUC, AR, or CR, were analyzed after $\log _{10}$ transformation to normalize the variance. Conclusions made from this analysis were similar to those from the analysis of the back-transformed data. The back-transformed data are presented in the tables.

\section{RESULTS}

\section{Milk Yield and Feed Intake}

Milk yield, milk composition, DMI, estimated ME intake, and BW have been reported in detail by Marett et al. (2015); these are summarized in Table 1. Briefly, milk yield, milk fat and protein yields, DMI, and ME intake decreased with increasing DIM and were greater in GRN compared with CON cows. Body weight in-

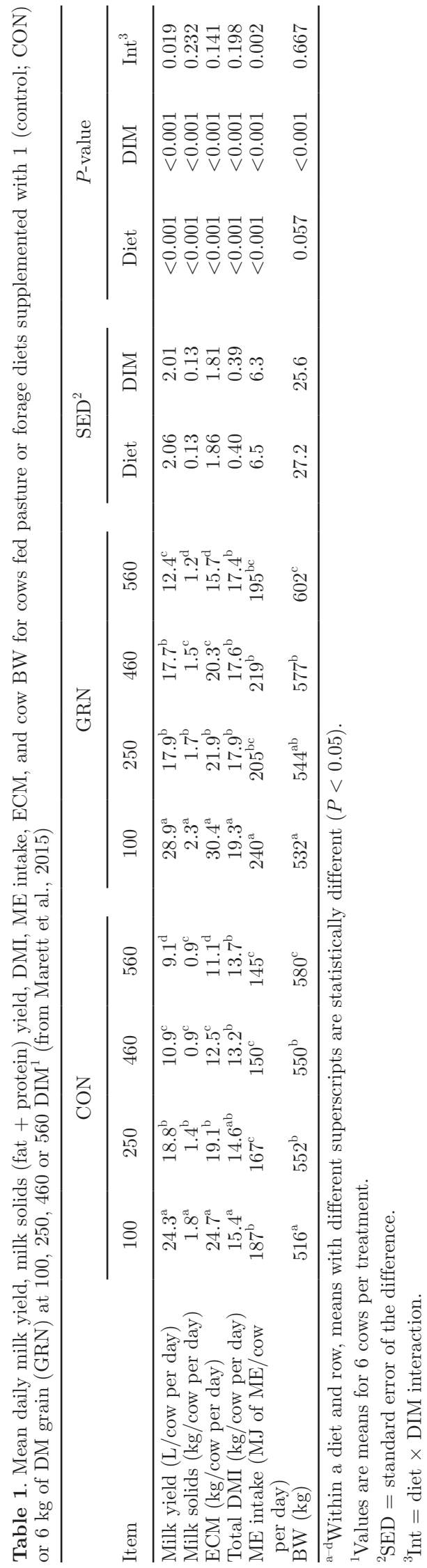


creased with increasing DIM and tended to be greater in GRN compared with the CON cows.

\section{Epinephrine Challenge}

Twenty-Four Hour Sampling. Data are presented as mean \pm maximum standard error of the difference. Mean plasma NEFA concentration decreased with increasing DIM (197, 121, 90, and $66 \pm 11.8 \mu M$ at 100, 250, 460, and 560 DIM, respectively; $P<0.001)$ and was lower in GRN- than CON-fed cows (107 vs. 129 $\pm 8.2 \mu M ; P=0.014$; Figure 1a). Plasma leptin concentration was lower before $300 \mathrm{DIM}$ and greater after 300 DIM $(0.71,0.58,1.27$, and $1.30 \pm 0.076 \mathrm{ng} / \mathrm{mL}$ at 100, 250, 460, and 560 DIM, respectively; $P<0.001$ ), and tended to be greater in GRN compared with CON cows overall $(1.02$ vs. $0.91 \pm 0.053 \mathrm{ng} / \mathrm{mL} ; P=0.070$; Figure 1b).
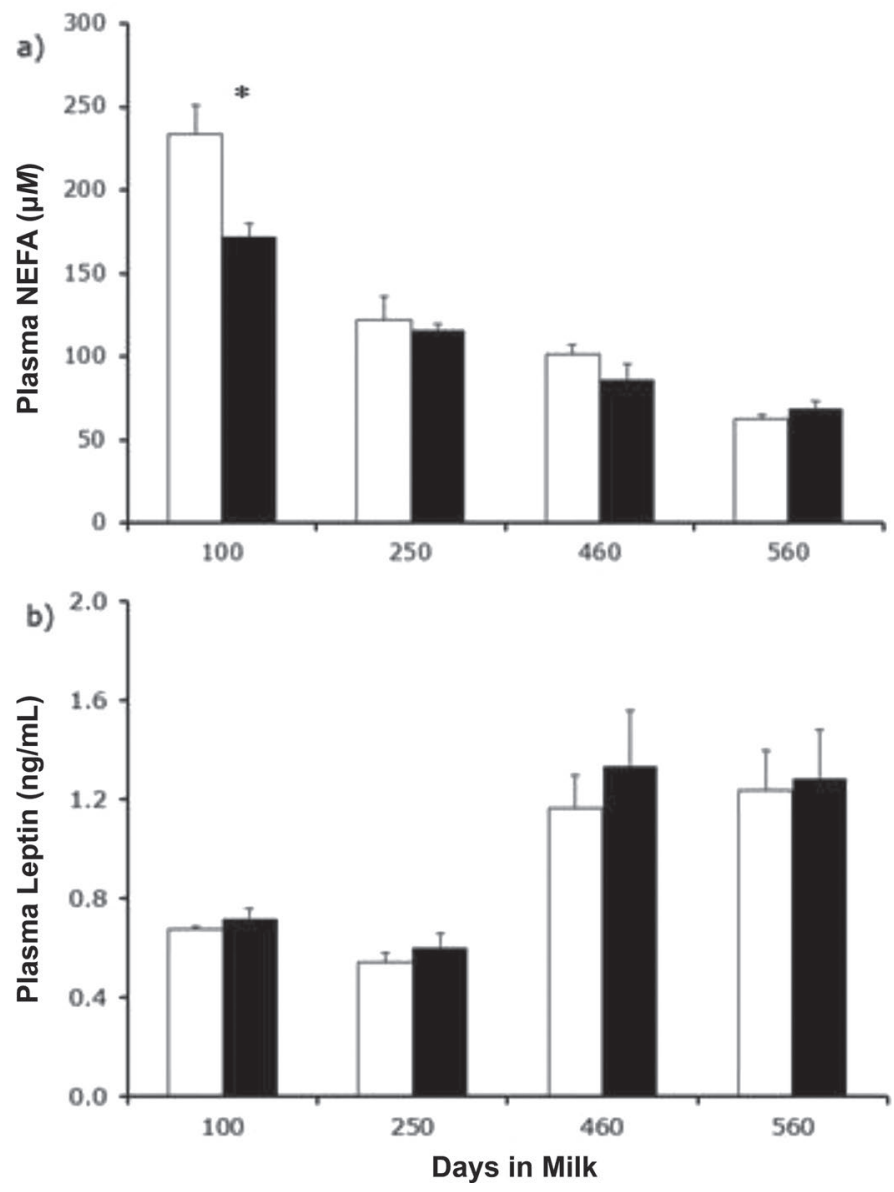

Figure 1. Mean plasma concentrations of 7 samples per cow over $24 \mathrm{~h}$ at each of $100,250,460$, and 560 DIM for (a) nonesterified fatty acids (NEFA) and (b) leptin of cows fed a diet supplemented with 1 (CON; open bars) or $6 \mathrm{~kg}$ of DM grain (GRN; solid bars). Data are means of 6 cows per treatment. Error bars represent SEM. Asterisks $(*)$ represent differences between treatments $(P<0.05)$.
Low-Dose Epinephrine. Basal plasma glucose concentration was greater in GRN compared with CON cows (4.0 vs. $3.8 \pm 0.11 \mathrm{~m} M, P=0.041)$. The infusion of $0.1 \mu \mathrm{g} / \mathrm{kg}$ of BW epinephrine caused a small increase in the plasma concentration of glucose (up to $25 \%$; Table 2, Figure 2). The maximum glucose concentration reached following the low dose tended to decrease with increasing DIM, being greatest at 100 DIM and lowest at $560 \mathrm{DIM}(4.9,4.4,4.6$, and $4.3 \pm 0.25 \mathrm{mM}$ at 100, 250, 460, and 560 DIM, respectively; $P=0.081$ ). The percent change in glucose was greatest at 100 DIM (25\%) compared with all other stages of the lactation $(13.5-14.5 \% ; P=0.035)$ and was not affected by diet. The glucose $\mathrm{AUC}_{0-10 \text { min }}$ was greatest at 460 DIM with no effect of diet.

Basal plasma NEFA concentration decreased as the lactation progressed $(349,261,335$, and $235 \pm 41.1 \mu M$ at $100,250,460$, and 560 DIM, respectively; $P=0.012$ ). We noted a small increase in the plasma concentration of NEFA following the infusion of the low dose of epinephrine (up to 70\%; Table 2, Figure 2). An interaction occurred between diet and DIM $(P=0.025)$ such that basal plasma NEFA concentration was greatest at 100 DIM in the GRN treatment, but greatest at 460 DIM in the CON treatment; NEFA concentration was lowest at 560 DIM in both treatments. The maximum plasma NEFA reached after the low dose of epinephrine was greatest at 100 , intermediate at 460 , and lowest at 250 and $560 \operatorname{DIM}(504,383,494$, and $369 \pm 42.4 \mu M$ at 100 , 250, 460, and 560 DIM, respectively; $P<0.001$ ) with no effect of diet; however, we observed an interaction between diet and DIM such that the maximum NEFA was greatest at 100 and lowest at 460 DIM in the GRN group and greatest at 460 and lowest at 250 DIM in the CON group. Neither the magnitude of change in plasma NEFA concentration nor the appearance rate of NEFA were affected by DIM or diet; however, the CR of NEFA slowed as DIM increased $(-2.7,-1.8$, -1.6 , and $-0.5 \pm 0.51 \% / \mathrm{min}$ at $100,250,460$, and 560 DIM, respectively; $P<0.001)$ and we found an interaction between DIM and diet $(P=0.033)$. The NEFA $\mathrm{AUC}_{0-30 \text { min }}$ was changed with DIM $(P=0.042)$, being greatest at 460 DIM but was not affected by diet.

High-Dose Epinephrine. Prior to the administration of the high dose of epinephrine, plasma concentrations of glucose and NEFA had returned to initial basal plasma concentrations. The infusion of $1.6 \mu \mathrm{g}$ of epinephrine/kg of BW was associated with a significant and rapid increase in the plasma concentration of glucose (up to $118 \%$ ) and NEFA (up to 180\%; Table 3 , Figure 3). The maximum glucose concentration was greater in the GRN than the CON group (8.0 vs. 7.3 $\pm 0.34 \mathrm{mM} ; P=0.033)$ following the administration of the high dose of epinephrine (Table 3; Figure 3), 
MARETT ET AL.

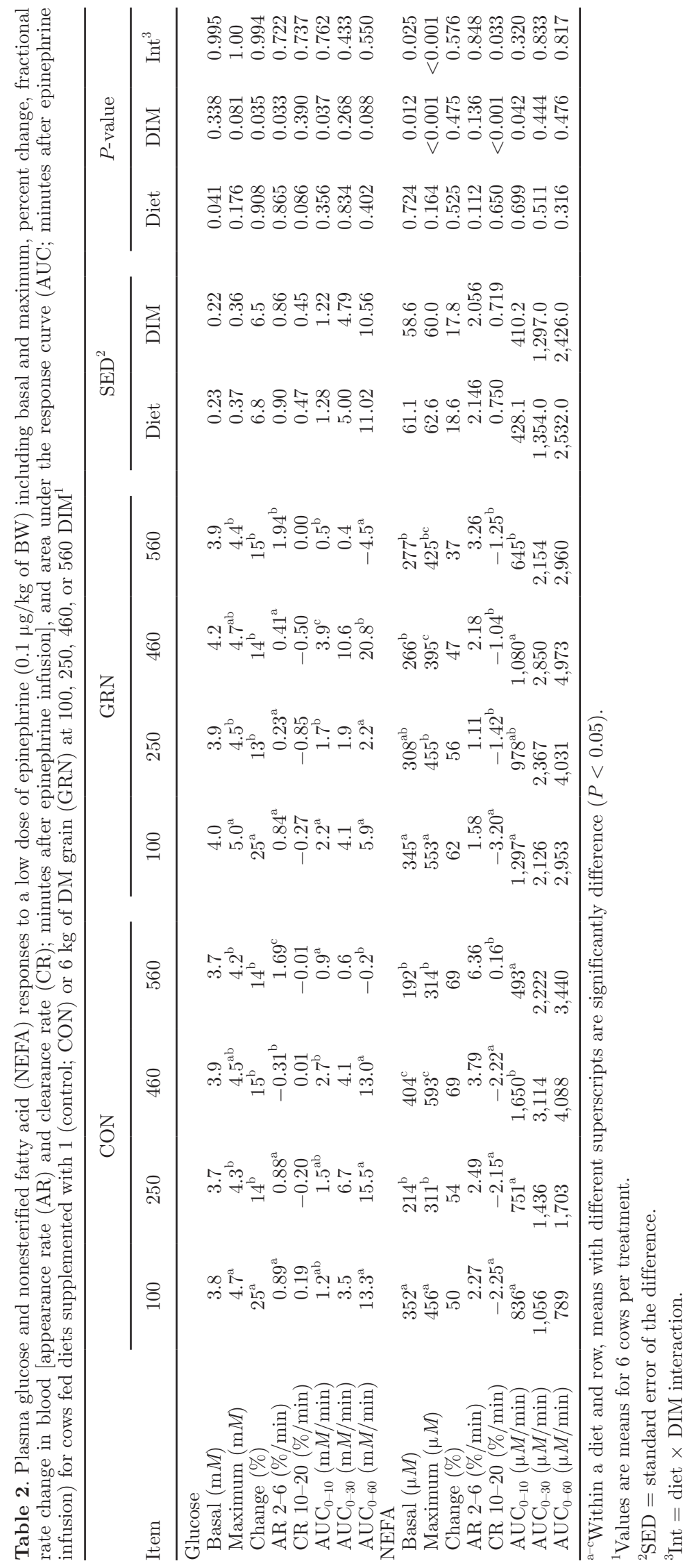


and tended to decrease as DIM increased $(8.3,7.8,7.6$, and $6.9 \pm 0.49 \mathrm{mM}$ at 100, 250, 460, and 560 DIM, respectively; $P=0.057)$. The percent change in plasma glucose concentration was greater in the GRN than the CON group (101 vs. $86 \pm 6.8 \% \mathrm{~m} M ; P=0.033$ ) and decreased as DIM increased (109, 96, 86, and $84 \pm$ $10 \mathrm{~m} M$ at 100, 250, 460, and 560 DIM, respectively; $P=0.043)$. We observed an interaction between diet and DIM for the maximum glucose concentration and percent change of glucose, such that in CON cows these were greatest at 100 and lowest at 560 DIM. However, in GRN cows, maximum glucose concentration and percent change of glucose were greatest at 250 , intermediate at 100 and 460, and lowest at 560 DIM. The AR of glucose was not affected by DIM, but was greater in GRN compared with the CON treatment (8.30 vs. 6.77 $\pm 0.523 \% / \mathrm{min} ; P=0.006)$. The glucose $\mathrm{CR}$ slowed as the lactation progressed $(-0.78,-0.64,-0.51$, and $-0.5 \pm 0.083 \% / \mathrm{min}$, at $100,250,460$, and $560 \mathrm{DIM}$, respectively; $P=0.003$ ) but was not affected by diet. We noted an interaction between DIM and diet for the glucose AUC measured for intervals between 0 to 10 , 0 to 30 , and 0 to $120 \mathrm{~min}(P=0.063,0.019,0.034$, respectively), being greatest at 100 DIM in the CON group but greatest at 250 and 460 DIM in the GRN group.

The maximum NEFA concentration reached after the high dose of epinephrine was greater in GRN than CON cows (780 vs. $651 \pm 48.1 \mu M ; P=0.007)$ and was greatest at $100 \mathrm{DIM}$, intermediate at 250 and 460 DIM, and lowest at 560 DIM $(954,697,729$, and $495 \pm$ $98.1 \mu M$ at 100, 250, 460, and 560 DIM, respectively; $P<0.001)$. We observed an interaction between DIM and diet for the maximum plasma NEFA concentration reached following the high dose of epinephrine. In the GRN group, the maximum NEFA consistently decreased throughout the lactation, but in the CON group the maximum NEFA concentration reached was highest at 100 DIM, followed by 460, 250, and then 560 DIM $(P=0.004)$. The percent change in plasma NEFA was greatest at 100 DIM, intermediate at 250 and 460 DIM, and lowest at 560 DIM (179, 147, 146, $109 \pm$ $21.0 \mu M$, respectively; $P=0.013)$ and was not affected by diet. The AR of NEFA was not affected by DIM or diet, but the CR of NEFA decreased with increasing DIM $(-5.64,-4.81,-3.05$, and $-1.53 \pm 0.568 \% /$
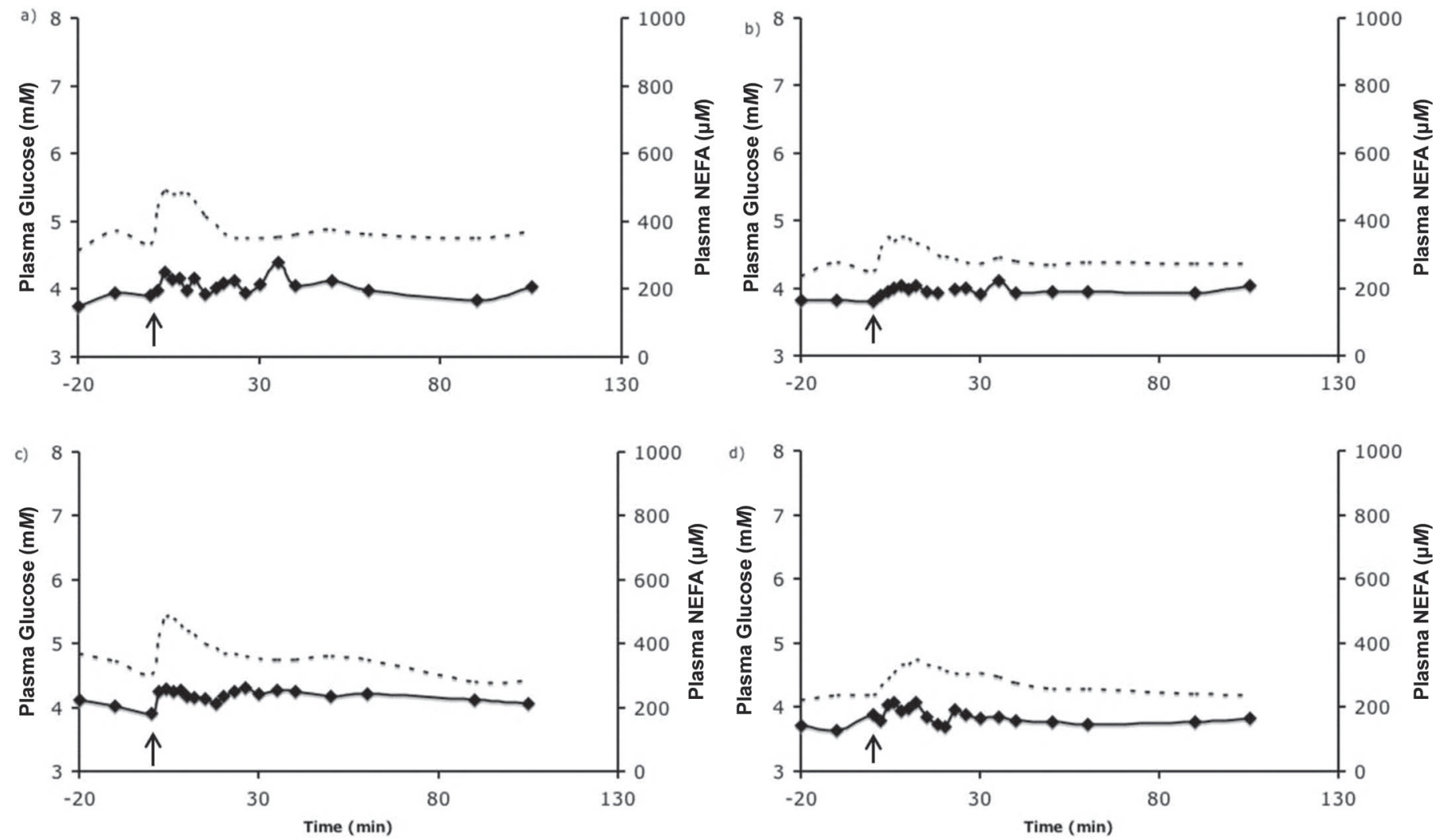

Figure 2. Plasma glucose ( $\bullet$ ) and nonesterified fatty acid (NEFA; - - ) response to a low dose of epinephrine $(0.1 \mu \mathrm{g} / \mathrm{kg}$ of BW) at time zero. Data are for challenges performed when cattle were at approximately (a) 100, (b) 250, (c) 460, and (d) 560 DIM. Data are combined for both treatments. Arrows denote epinephrine infusion at time zero. Pooled SE for each stage of lactation were $0.30,0.33,0.18$, and 0.18 for glucose, and 56.4, 53.1, 62.1 and 66.8 for NEFA, respectively. 
MARETT ET AL.

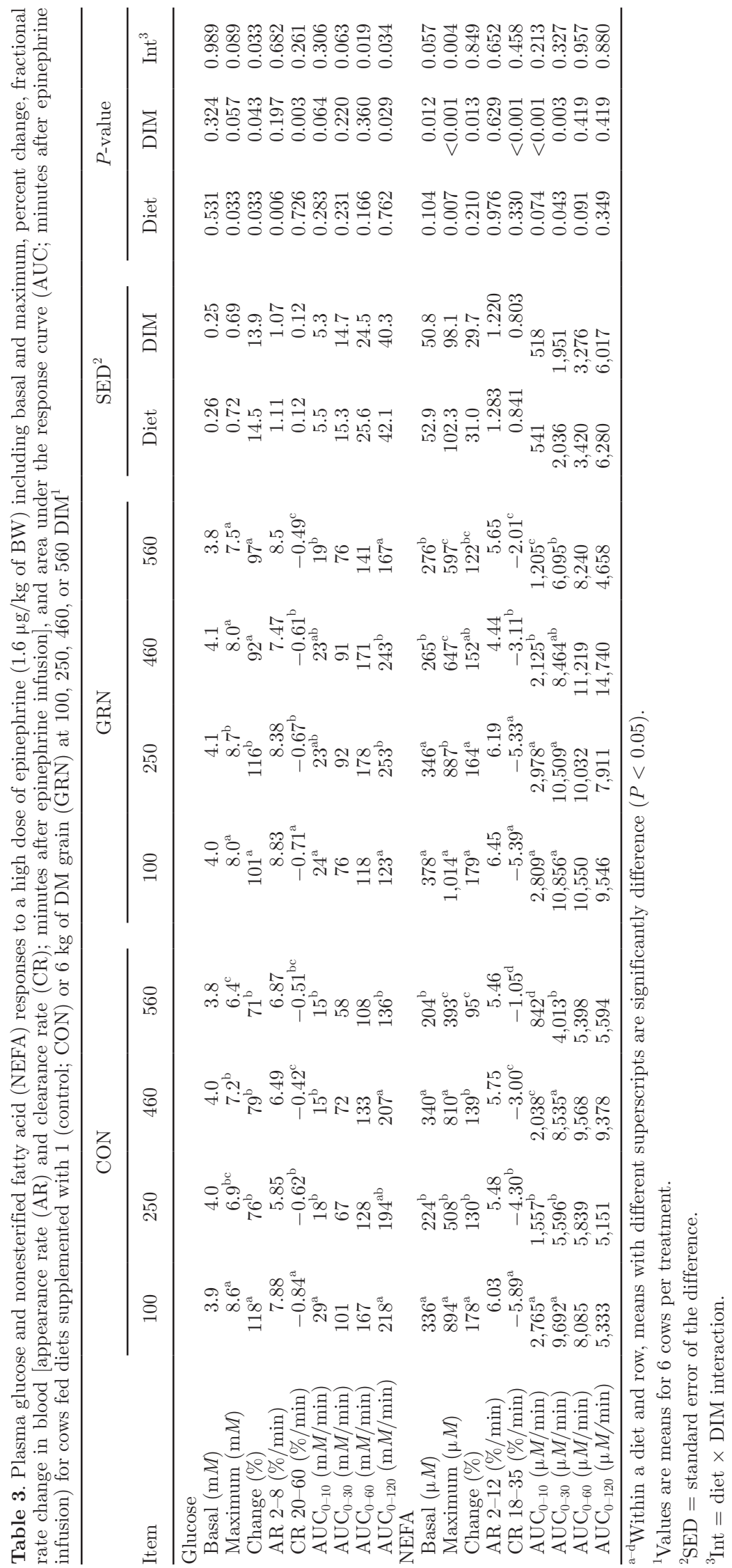


min at 100, 250, 460, and 560 DIM, respectively; $P$ $<0.001)$. The $\mathrm{AUC}_{0-10 \text { min }}$ decreased with increasing $\operatorname{DIM}(2,787,2,267,2,082$, and $1,023 \pm 366.3 \mu \mathrm{M} / \mathrm{min}$ at 100, 250, 460, and 560 DIM, respectively; $P<0.001$ ), and tended to be greater in the GRN compared with CON treatment $(P=0.074$, respectively) with a similar trend in $\mathrm{AUC}_{0-30 \text { min }}$.

\section{DISCUSSION}

The epinephrine challenge has been used in sows (Tilton et al., 1999) and cows (McNamara et al., 1985; Chilliard et al., 1998; Theilgard et al., 2002), including some fed pasture (Kolver et al., 2001), to investigate the responsiveness of adipose tissue to hydrolyze lipids to form free fatty acids and glycerol. To our knowledge, this is the first report of plasma glucose and NEFA responses to an epinephrine challenge in dairy cows during an extended lactation of up to $670 \mathrm{~d}$.

The mean 24-h and basal concentrations of plasma NEFA and leptin in this experiment showed that fat mobilization was decreased and fat mass increased as an extended lactation progressed. These changes represent an increase in the partitioning of nutrients away from milk production and toward body reserves, in particular adipose tissue. Adipose tissue is one of the most important stores of energy that is homeorhetically regulated to support lactation in Holstein-Friesian cows (Bauman, 2000). Some of the circulating NEFA that arise from lipolysis in adipose tissue are used by the mammary gland as a substrate for milk fat synthesis (Drackley et al., 2001). Cows partition energy toward body reserves, primarily in the form of adipose tissue, at the expense of milk yield during the later stages of an extended lactation (Kay et al., 2009; Delany et al., 2010; Marett et al., 2011).

Sensitivity to the low dose of epinephrine was greatest at 100 DIM. The magnitude of the plasma glucose and NEFA responses to the low dose of epinephrine was greatest at 100 DIM and lowest at 560 DIM. This supports our first hypothesis, that the sensitivity to epinephrine would decrease as the lactation progressed. The NEFA response showed a clear peak in NEFA concentration, indicating high sensitivity to catecholamine
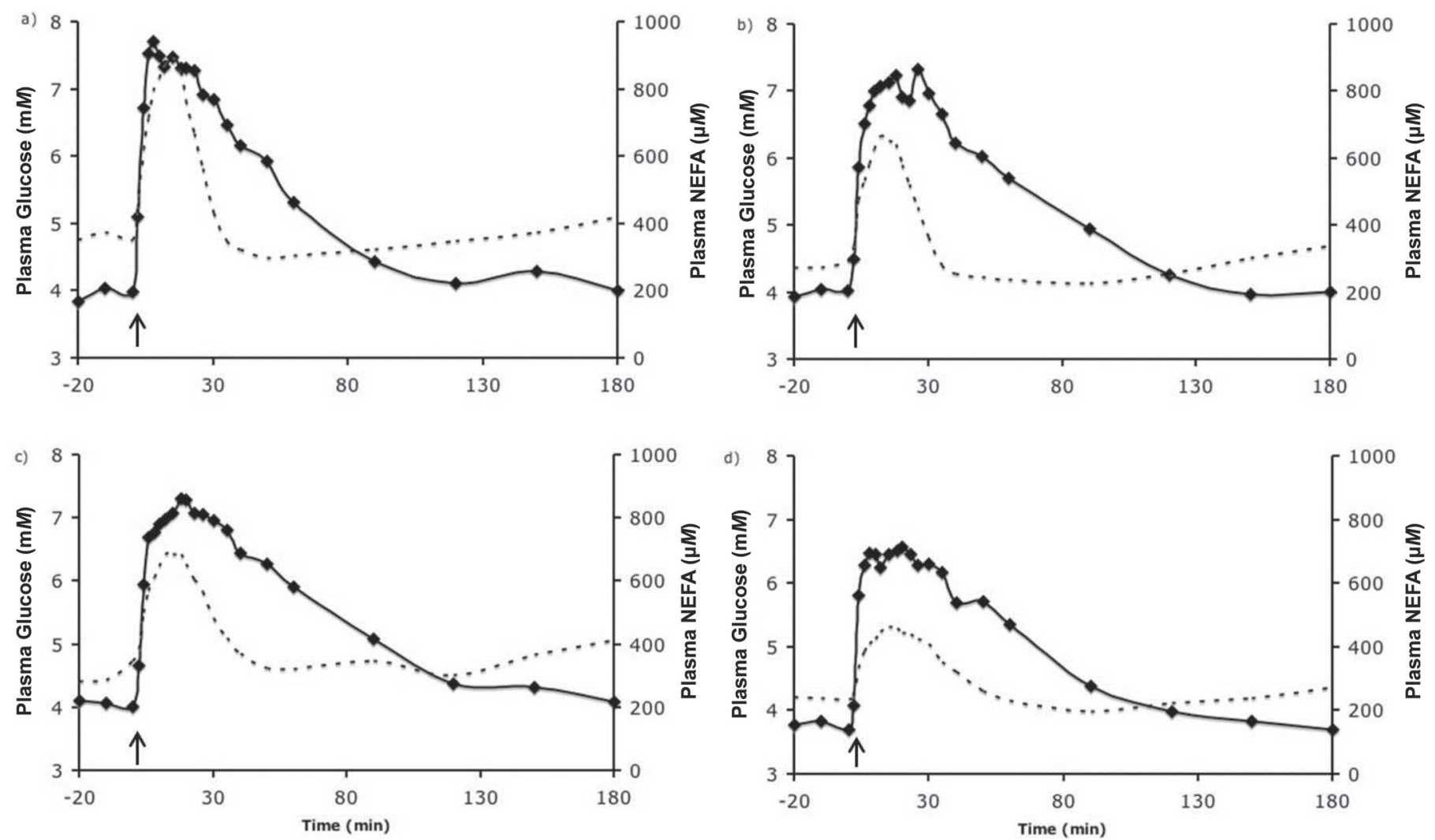

Figure 3. Plasma glucose $(\bullet)$ and nonesterified fatty acid (NEFA; - - ) response to a high dose of epinephrine $(1.6 \mu \mathrm{g} / \mathrm{kg}$ of BW) at time zero. Data are for challenges performed when cattle were at approximately (a) 100, (b) 250, (c) 460, and (d) 560 DIM. Data are combined for both treatments. Arrows denote epinephrine infusion at time zero. Pooled SE for each stage of lactation were 0.30, 0.33, 0.18, and 0.18 for glucose, and 56.4, 53.1, 62.1, and 66.8 for NEFA, respectively. 
stimulated lipolysis at times of increased requirements for milk production. However, the glucose response was muted, indicative of low stimulation of hepatic glycogenolysis or gluconeogenesis, in response to the low dose of epinephrine. These results are in agreement with previous research that has shown that the greatest requirement for lipid mobilization and the time of greatest lipolytic sensitivity and responsiveness in dairy cows is early lactation (McNamara 1988). Although the data were from cows at around 100 DIM, these data concur with previous research that showed greater sensitivity to catecholamines in early lactation in sows (Tilton et al., 1999) and cows (Theilgard et al., 2002) and in lactating compared with nonlactating animals, reflecting the catabolic status of the animals during lactation (Dunshea et al., 1990).

The plasma NEFA response to epinephrine in the current experiment may reflect the overall physiological state and requirements for milk yield of the cows at a given stage of the lactation due to homeorhetic changes. In the current experiment, the responsiveness to epinephrine changed throughout the lactation. This pattern was similar to that of milk yield throughout extended lactations, with increases in early lactation and again at approximately 400 to 500 DIM (Auldist et al., 2007; Kolver et al., 2007; Marett et al., 2011). The greatest response of both plasma glucose and NEFA to the high dose of epinephrine occurred at 100 DIM and the lowest response occurred at 560 DIM. This coincided with the greatest and lowest milk production at 100 and 560 DIM, respectively, supporting our second hypothesis, that the responsiveness to epinephrine would decrease with increasing DIM. The current data show the pattern of basal plasma NEFA concentration throughout an extended lactation to be similar to our previous report in the same cows (Marett et al., 2015) and in other experiments (Kay et al., 2009; Marett et al., 2011). This gives an indication of the lipolytic potential of the cows throughout an extended lactation, but does not account for an increase in lipogenesis that is likely to occur throughout the latter stages of the lactation, especially an extended lactation.

The high dose of epinephrine in the current experiment resulted in hyperglycemia, the magnitude of which decreased throughout the extended lactation. The glucose response to epinephrine primarily indicates the level of glycogen stores in the liver, though it can also indicate the level of hepatic gluconeogenesis (Brockman and Laarveld, 1986; Rose et al., 2009). These types of responses have been documented in dogs, humans (Sherwin and Sacca, 1984), and dairy cows (Sechen et al., 1990; Kolver et al., 2001; Rose et al., 2009). The peak glucose response in the current experiment was greatest at 100 DIM, concurrent with a significantly greater percentage change in plasma glucose concentration than later in the lactation; in addition, the rate of glucose clearance was greater at 100 DIM. These data indicate that not only is the stimulation of hepatic glycogenolysis or gluconeogenesis greater, but the uptake of glucose by either the mammary gland or peripheral tissues is also greater at times of higher milk yield.

The greatest responsiveness to epinephrine was observed concurrent with the enhanced ability of the mammary gland to use available glucose and NEFA for milk production. Nonesterified fatty acid removal from plasma is dependent on tissue uptake and the rate of oxidation or re-esterification of fatty acids. Increased rates of NEFA clearance from plasma at 100 DIM following the high dose of epinephrine indicate greater rates of re-esterification of fatty acids, in addition to uptake by the mammary gland as a substrate for milk fat synthesis or uptake by other tissues for energy use (e.g., liver). The responsiveness to epinephrine decreased even though the fat mass available was likely to be greater in later lactation, given the increased plasma leptin concentration. McNamara (1988) showed an increase in the maximum lipolytic response to catecholamines with the onset of lactation, with peak responsiveness occurring around the time of peak milk production. Increased rates of lipolysis are generally, although not always, associated with decreased rates of fatty acid re-esterification and lipogenesis throughout lactation (McNamara, 1988). The rate at which NEFA enters the plasma reflects lipolysis, but gives no indication of the re-esterification of NEFA. This can only be determined by simultaneously measuring NEFA and glycerol (Dunshea et al., 1990). However, glycerol is used as a glucose precursor and its release is stimulated by epinephrine. Therefore, it is not surprising that the glucose and NEFA data conform to a similar pattern throughout the extended lactation. The adipose tissue of cows with greater milk yield also has greater rates of lipolysis at the time of stimulation with epinephrine (McNamara, 1989). This is consistent with more recent reports of basal and stimulated lipolysis in incubated bovine adipose tissue, which showed that lipolysis at 270 DIM was similar to prepartum levels but that basal lipolysis was $\sim 10 \%$ greater and stimulated lipolysis was $\sim 60 \%$ greater at 90 DIM than $30 \mathrm{~d}$ prepartum (Sumner and McNamara, 2007).

We found no effect of diet on the sensitivity to epinephrine, in support of the third hypothesis; however, the responsiveness of plasma glucose and NEFA to epinephrine was typically greater in GRN compared with CON cows. Consequently, the fourth hypothesis is rejected. Throughout the lactation, milk yield was greater in the GRN than the CON treatment, making the differentiation between the effect of diet and the 
effect of milk yield on the sensitivity and responsiveness to epinephrine difficult. Interestingly, a second peak in sensitivity and responsiveness to epinephrine occurred at 460 DIM, which coincided with the second spring (peak in pasture availability and quality), and this was more pronounced for the GRN treatment. This indicates an ability to shift adipose tissue metabolism midway through an extended lactation, possibly according to dietary energy intake and milk production. It appears that interactions exist between environmental and genetic factors in the regulation of lipolysis (Roche et al., 2009; Hills et al., 2015). Kolver et al. (2001) reported that the plasma glycerol response to epinephrine was greater during early lactation in non-New Zealand Holstein-Friesian cows when offered a pasture diet versus a TMR, indicating greater rates of lipolysis when energy is limiting. With the current small data set it is not possible to differentiate between the effect of increased intake of grain, increased milk yield (or genetic merit), or stage of lactation on the overall responsiveness of adipose tissue to epinephrine throughout the extended lactation.

It is possible that cows with greater lactation persistency have greater lipolytic responsiveness as a result of interactions with other homeorhetic hormones, such as GH (synonymous with somatotropin) and insulin. Our previous reports revealed that cows in the $\mathrm{CON}$ treatment had greater plasma GH concentrations (Marett et al., 2014) and lower plasma insulin concentrations (Marett et al., 2017) compared with those in the GRN treatment as a 670-d lactation progressed. Experiments that have involved cows treated with bST have investigated the responsiveness to epinephrine of cows with increased milk yield. McCutcheon and Bauman (1986) and Sechen et al. (1989) found greater increases in plasma NEFA concentrations in lactating dairy cows treated with bST compared with nontreated cows. It is unclear whether the responsiveness to epinephrine returned to prelactation levels by the end of the extended lactation, as this was not measured. However, the data indicate a greater lipolytic responsiveness of adipose tissue in the GRN treatment and a greater ability to mobilize energy stores in bST-treated cows with greater milk yield. In the current experiment, cows with greater milk yield had greater responsiveness to epinephrine as the lactation progressed; this is indicative of increased lipolysis, but we cannot confirm this with certainty due to a lack of concurrent glycerol measurements (Dunshea et al., 1990). Data presented by Marett et al. (2017) in the same cows, showed that the GRN treatment resulted in greater plasma insulin concentrations, which supports lipogenesis and inhibits lipolysis as the lactation progressed. Further, the responsiveness to an insulin challenge was increased, in terms of the antilipolytic response to insulin, from 100 to 560 DIM. This indicates a large increase in the rate of lipogenesis throughout the extended lactation, which may mask the overall rates of lipolysis in the late stages of extended lactation.

For the current experiment, it is not possible to compare the responses to epinephrine in the extended phase of the lactation (460 and 560 DIM) to prepartum levels of lipolysis, as no measures were undertaken before 100 DIM. However, given the increasing plasma leptin concentration and decreasing plasma NEFA (current data) and GH (Marett et al., 2014) concentrations in these cows beyond 300 DIM, we can assume that the rates of lipolysis were low and that rates of lipogenesis were high and far exceeded that of early lactation. This has implications for the management of cows using extended lactations; for example, Delany et al. (2010) demonstrated that cows fed in excess of their requirements (in the form of a TMR) gained excess body condition and were unable to sustain milk production to $670 \mathrm{~d}$, unlike their pasture-based counterparts that were able to continue milking. There may also have been variable mobilization of visceral versus subcutaneous fat depots (De Koster et al., 2016). Evidence suggests differential mobilization of adipose stores from visceral and subcutaneous tissues in lactating and nonlactating cows (Hostens et al., 2012; Drackley et al., 2014). Further, over-conditioned cows are predisposed to excessive mobilization of body fat (De Koster et al., 2016). In light of this, farmers and herd managers will need to be aware of the body condition of cows managed for extended lactations and avoid over-feeding to avoid excess fatness. Maintaining a suitable body condition will avoid increasing the incidence of metabolic disorders during the time around calving and early lactation that may arise from excess fat mobilization (Roche et al., 2009).

\section{CONCLUSIONS}

Being able to identify cows with greater persistency would allow farmers to make management decisions for breeding and nutrition in cows managed for extended lactations. The results of the current experiment support the original hypotheses, and the changes in sensitivity and responsiveness to a catecholamine challenge supported previous data that indicate that the partitioning of nutrients is increasingly directed toward body reserves as an extended lactation progresses. Sensitivity and responsiveness to exogenous epinephrine were greater earlier in lactation and at times of increased priority of milk yield. Sensitivity to epinephrine and responsiveness were decreased with decreasing milk yield, as measured by the appearance of NEFA from adipose tissue in the plasma. The stimulation of 
hepatic gluconeogenesis and glycogenolysis in response to epinephrine was greatest earlier in lactation, and the uptake of glucose was decreased throughout times of decreased requirement beyond 300 DIM. Increased plasma glucose and NEFA clearance rates before 300 DIM indicated greater uptake of these substrates by the mammary gland for milk synthesis earlier in lactation. These results support previous findings that major changes occur in terms of adipose tissue metabolism during extended lactations. The endocrine regulation of nutrient partitioning throughout traditional and extended lactation is complex, with many interactions between stage of lactation, diet, and milk yield potential. These data have implications for the management of dairy cows throughout lactation.

\section{ACKNOWLEDGMENTS}

The authors thank K. DiGiacomo, D. Mapleson, G. Morris, T. Hookey, and A. McDonald in addition to technical and farm staff (Department of Economic Development, Jobs, Transport and Resources, Ellinbank, Australia). This work was financially supported by the Geoffrey Gardiner Dairy Foundation (Melbourne, Australia), the University of Melbourne (Melbourne, Australia) and Department of Economic Development, Jobs, Transport and Resources, Victoria.

\section{REFERENCES}

Auldist, M. J., C. Grainger, K. L. Macmillan, L. C. Marett, M. Hannah, B. J. Leury, and W. J. Wales. 2011. Feed conversion efficiency and marginal milk production responses of pasture-fed dairy cows offered supplementary grain during an extended lactation. Anim. Prod. Sci. 51:204-209. https://doi.org/10.1071/AN10170.

Auldist, M. J., G. N. O'Brien, D. J. Cole, K. L. Macmillan, and C. Grainger. 2007. Effects of varying lactation length on milk production capacity of cows in pasture-based dairying systems. J. Dairy Sci. 90:3234-3241. https://doi.org/10.3168/jds.2006-683.

Baird, D. B. 1994. The design of experiments with covariates. PhD thesis. University of Otago, Otago, New Zealand.

Bauman, D. E. 2000. Regulation of nutrient partitioning during lactation: Homeostasis and homeorhesis revisited. Pages 311-328 in Ruminant Physiology: Digestion, Metabolism, Growth and Reproduction. P. B. Cronje, ed. CAB International, New York, NY.

Blache, D., R. L. Tellam, L. M. Chagas, M. S. Blackberry, P. E. Vercoe, and G. B. Martin. 2000. Level of nutrition affects leptin concentrations in plasma and cerebrospinal fluid in sheep. J. Endocrinol. 165:625-637. https://doi.org/10.1677/joe.0.1650625.

Brockman, R. P., and B. Laarveld. 1986. Hormonal regulation of metabolism in ruminants: A review. Livest. Prod. Sci. 14:313-334. https://doi.org/10.1016/0301-6226(86)90012-6.

Chilliard, Y., A. Ferlay, L. Depres, and F. Bocquier. 1998. Plasma nonesterified fatty acid response to a beta-adrenergic challenge before or after feeding in energy underfed or overfed, dry or lactating cows. Ann. Sci. 67:213-223.

Collier, R. J., J. P. McNamara, C. R. Wallace, and M. H. Dehoff. 1984. A review of endocrine regulation of metabolism during lactation. J. Anim. Sci. 59:498-510.

De Koster, J., W. Van den Broeck, L. Hulpio, E. Claeys, M. Van Eetvelde, K. Hermans, M. Hostens, V. Fievez, and G. Opsomer. 2016.
Influence of adipocyte size and adipose depot on the in vitro lipolytic activity and insulin sensitivity of adipose tissue in dairy cows at the end of the dry period. J. Dairy Sci. 99:2319-2328. https:// doi.org/10.3168/jds.2015-10440.

Delany, K. K., K. L. Macmillan, C. Grainger, P. C. Thomson, D Blache, K. R. Nicholas, and M. J. Auldist. 2010. Blood plasma concentrations of metabolic hormones and glucose during extended lactation in grazing cows or cows fed a total mixed ration. J. Dairy Sci. 93:5913-5920. https://doi.org/10.3168/jds.2010-3609.

Drackley, J. K., T. R. Overton, and G. N. Douglas. 2001. Adaptations of glucose and long-chain fatty acid metabolism in liver of dairy cows during the periparturient period. J. Dairy Sci. 84:E100-E112. https://doi.org/10.3168/jds.S0022-0302(01)70204-4.

Drackley, J. K., R. L. Wallace, D. Graugnard, J. Vasquez, B. F. Richards, and J. J. Loor. 2014. Visceral adipose tissue mass in nonlactating dairy cows fed diets differing in energy density. J. Dairy Sci. 97:3420-3430. https://doi.org/10.3168/jds.2014-8014.

Dunshea, F. R., A. W. Bell, and T. E. Trigg. 1990. Non-esterified fatty acid and glycerol kinetics and fatty acid re-esterification in goats during early lactation. Br. J. Nutr. 64:133-145. https://doi.org/10 .1079/BJN19900016.

Ferrannini, E., S. Camastra, S. W. Coppack, D. Fliser, A. Golay, and A. Mitrakou. 1997. Insulin action and non-esterified fatty acids. Proc. Nutr. Soc. 56:753-761.

Grainger, C., M. J. Auldist, G. O'Brien, K. L. Macmillan, and C. Culley. 2009. Effect of type of diet and energy intake on milk production of Holstein-Friesian cows with extended lactations. J. Dairy Sci. 92:1479-1492. https://doi.org/10.3168/jds.2008-1530.

Hills, J. L., W. J. Wales, F. R. Dunshea, S. C. Garcia, and J. R. Roche. 2015. Invited review: An evaluation of the likely effects of individualized feeding of concentrate supplements to pasture-based dairy cows. J. Dairy Sci. 98:1363-1401. https://doi.org/10.3168/ jds.2014-8475.

Hostens, M., V. Fievez, J. L. M. R. Leroy, J. Van Ranst, B. Vlaeminck, and G. Opsomer. 2012. The fatty acid profile of subcutaneous and abdominal fat in dairy cows with left displacement of the abomasum. J. Dairy Sci. 95:3756-3765. https://doi.org/10.3168/ jds.2011-5092

Johnson, M. M., and J. P. Peters. 1993. Technical note: An improved method to quantify nonesterified fatty acids in bovine plasma. J Anim. Sci. 71:753-756.

Kay, J. K., C. V. C. Phyn, J. F. Roche, and E. S. Kolver. 2009. Extending lactation in pasture-based dairy cows II: Effect of genetic strain and diet on plasma hormone and metabolite concentrations. J. Dairy Sci. 92:3704-3713. https://doi.org/10.3168/jds.2008-1976.

Kolver, E. S., J. R. Roche, C. R. Burke, J. K. Kay, and P. W. Aspin. 2007. Extending lactation in pasture-based dairy cows: I. Genotype and diet effect on milk production. J. Dairy Sci. 90:55185530. https://doi.org/10.3168/jds.2007-0324.

Kolver, E. S., J. R. Roche, M. J. De Veth, and T. R. Mackle. 2001. Lipolytic response of New Zealand and overseas Holstein-Friesian dairy cows challenged with epinephrine. Proc. N. Z. Soc. Anim. Prod. 61:48-51

Liesman, J. S., J. P. McNamara, A. V. Capuco, M. Binelli, W. K. Vanderkooi, R. S. Emery, H. A. Tucker, and W. M. Moseley. 1995. Comparison of growth hormone-releasing factor and somatotropin: Lipid and glucose metabolism in dairy cows. J. Dairy Sci. 78:2159 2166. https://doi.org/10.3168/jds.S0022-0302(95)76843-6.

Marett, L. C., M. J. Auldist, C. Grainger, W. J. Wales, D. Blache, K. L. Macmillan, and B. J. Leury. 2011. Temporal changes in plasma concentrations of hormones and metabolites in pasture-fed dairy cows during extended lactation. J. Dairy Sci. 94:5017-5026. https://doi.org/10.3168/jds.2011-4272.

Marett, L. C., M. J. Auldist, P. J. Moate, W. J. Wales, K. L. Macmillan, F. R. Dunshea, and B. J. Leury. 2015. Response of plasma glucose, insulin, and nonesterified fatty acids to intravenous glucose tolerance tests in dairy cows during a 670-day lactation. J. Dairy Sci. 98:179-189. https://doi.org/10.3168/jds.2014-8205.

Marett, L. C., M. J. Auldist, W. J. Wales, K. L. Macmillan, K. DiGiacomo, and B. J. Leury. 2014. Evaluation of growth hormone response to insulin-induced hypoglycaemia in dairy cattle during 
a 670-day lactation. Anim. Prod. Sci. 54:1323-1327. https://doi .org/10.1071/AN14224.

Marett, L. C., M. J. Auldist, W. J. Wales, K. L. Macmillan, F. R. Dunshea, and B. J. Leury. 2017. Responses of plasma glucose and nonesterified fatty acids to intravenous insulin tolerance tests in dairy cows during a 670-day lactation. J. Dairy Sci. 100:32723281. https://doi.org/10.3168/jds.2016-11985.

McCutcheon, S. N., and D. E. Bauman. 1986. Effect of chronic growth hormone treatment responses to epinephrine and thyrotropin-releasing hormone in lactating cows. J. Dairy Sci. 69:44-51. https:// doi.org/10.3168/jds.S0022-0302(86)80368-X.

McNamara, J. P. 1988. Regulation of bovine adipose tissue metabolism during lactation. 4. Dose-responsiveness to epinephrine as altered by stage of lactation. J. Dairy Sci. 71:643-649. https://doi .org/10.3168/jds.S0022-0302(88)79602-2.

McNamara, J. P. 1989. Regulation of bovine adipose tissue metabolism during lactation 5. Relationships of lipid synthesis and lipolysis with energy intake and utilization. J. Dairy Sci. 72:407-418.

McNamara, J. P., M. H. Dehoff, R. J. Collier, and F. W. Bazer. 1985. Adipose tissue fatty acid metabolism during pregnancy in swine. J. Anim. Sci. 61:410-415.

McNamara, J. P., and J. K. Hillers. 1986. Regulation of bovine adipose tissue metabolism during lactation. 2. Lipolysis response to milk production and energy intake. J. Dairy Sci. 69:3042-3050. https:// doi.org/10.3168/jds.S0022-0302(86)80767-6.

NHMRC. 2004. Australian Code of Practice for the Care and Use of Animals for Scientific Purposes. 7th ed. National Health and Medical Research Council (NHMRC), ed. Australian Government, Canberra, Australia.

Roche, J. R., N. C. Friggens, J. K. Kay, M. W. Fisher, K. J. Stafford, and D. P. Berry. 2009. Invited review: Body condition score and its association with dairy cow productivity, health, and welfare. J. Dairy Sci. 92:5769-5801. https://doi.org/10.3168/jds.2009-2431.
Rose, M. T., T. E. C. Weekes, and P. Rowlinson. 2009. Relationship between the milk yield response to short-term bovine somatotropin treatment and the lipolytic response to adrenaline in dairy cows. Domest. Anim. Endocrinol. 36:24-31. https://doi.org/10 .1016/j.domaniend.2008.09.001.

Rubinstein, D., S. Chiu, J. Naylor, and J. C. Beck. 1964. Lipolytic action of epinephrine in adipose tissue homogenates. Am. J. Physiol. 206:149-152.

Sechen, S. J., F. R. Dunshea, and D. E. Bauman. 1990. Somatotropin in lactating cows: Effect on response to epinephrine and insulin. Am. J. Physiol. 258:E582-E588.

Sechen, S. J., S. N. McCutcheon, and D. E. Bauman. 1989. Response to metabolic challenges in early lactation dairy cows during treatment with bovine somatotropin. Domest. Anim. Endocrinol. 6:141-154. https://doi.org/10.1016/0739-7240(89)90043-X.

Sherwin, R. S., and L. Sacca. 1984. Effect of epinephrine on glucose metabolism in humans: Contribution of the liver. Am. J. Physiol. 247:E157-E165.

Sumner, J. M., and J. P. McNamara. 2007. Expression of lipolytic genes in the adipose tissue of pregnant and lactating Holstein dairy cattle. J. Dairy Sci. 90:5237-5246. https://doi.org/10.3168/ jds.2007-0307.

Theilgard, P., N. C. Friggens, K. H. Sloth, and K. L. Ingvarsten. 2002. The effect of breed, parity and fatness on the lipolytic response of dairy cows. Ann. Sci. 75:209-219.

Tilton, S. L., P. S. Miller, A. J. Lewis, D. E. Reese, and P. M. Ermer. 1999. Addition of fat to the diets of lactating cows: I effects on milk production and composition and carcass composition of the litter at weaning. J. Anim. Sci. 77:2491-2500.

Wagle, S. R., F. Hofmann, and K. Decker. 1976. Studies on the stimulation of gluconeogenesis and lipolysis by glucagon and epinephrine in isolated rat kupffer cells. Biochem. Biophys. Res. Commun. 71:857-863. https://doi.org/10.1016/0006-291X(76)90910-4. 